DOI: $10.21767 / 2572-2107.100016$

\title{
The Prognostic Value of P16 Expression in Laryngeal Squamous Cell Carcinomas: A Large Cohort Study of Chinese Patients
}

\author{
Pallavi K Galera ${ }^{1 *}$, Kai Chen ${ }^{2,3^{*}}$, Weijun $\mathrm{Ye}^{2,3}$,Qiuliang Wu ${ }^{3,4}$ and Zhong Jiang ${ }^{1}$ \\ ${ }^{1}$ Department of Pathology, University of Massachusetts Medical School, Worcester, MA, USA \\ ${ }^{2}$ Department of Radiotherapy, Cancer Center, SunYat-sen University, Guangzhou, Guangdong, China \\ ${ }^{3}$ State Key Laboratory of Oncology in South China, Guangzhou, Guangdong, China \\ ${ }^{4}$ Department of Pathology, Cancer Center, SunYat-sen University, Guangzhou, Guangdong, China
}

Corresponding author: Zhong Jiang, M.D, Department of Pathology, University of Massachusetts Medical School, Worcester, MA 01605, USA, Tel:508-793-6166; E-mail: jiangz@ummhc.org

*The authors are equal contributors to this study and they are considered as co-first authors.

Received date: April 24, 2017; Accepted date: May 02, 2017; Published date: May 10, 2017

Citation: Galera PK, Chen K, Ye W, et al. The Prognostic Value of P16 Expression in Laryngeal Squamous Cell Carcinomas: A Large Cohort Study of Chinese Patients. Head Neck Cancer Res. 2017, 2:1.

\section{Abstract}

Background: In the United States and Europe, about $15-35 \%$ of head and neck squamous cell carcinoma are caused by human papillomavirus (HPV). The expression of p16 has been demonstrated to be a favorable biomarker for patients with head and neck squamous cell carcinoma. However, p16 expression and its prognostic value in laryngeal squamous cell carcinoma in Chinese patients are unknown. We aim to investigate p16 expression and its prognostic value in a large group of Chinese patients with laryngeal squamous cell carcinoma.

Design: A total of 236 patients with laryngeal squamous cell carcinomas (laryngectomy, $n=110$; biopsy, $n=126$ ) obtained from the Surgical Pathology file (2000-2005), Cancer Center of SunYat-sen University, Guangzhou, People's Republic of China were examined by immunohistochemistry for p16 expression. Overall survival was measured from the date of laryngectomy or biopsy to the date of death, and was censored from the date of last follow-up. Median follow-up period was 5 years and 3 months (63 months, range 7-123 months).

Results: Clinical characteristics of the 236 patients with laryngeal squamous cell carcinoma showed that age, tumor stage and grade, and vital status (alive or dead) were not associated with p16 expression. Only 43 of 236 (18\%) laryngeal squamous cell carcinomas expressed p16. Kaplan-Meier analysis showed that the 10 -year overall survival rate was similar in patients with p16 positive tumors and patients with p16 negative tumors ( $31 \%$ vs. $34 \% ; \mathrm{P}=0.28 ; 95 \%$ confidence interval $[\mathrm{Cl}], 0.34$ to 1.37 ).

Conclusion: The expression of p16 was found in only $18 \%$ Chinese patients with laryngeal squamous cell carcinomas. Unlike Caucasian patients, this large cohort study provides the first evidence that $\mathrm{p} 16$ positivity is not a favorable biomarker for patients with laryngeal squamous cell carcinomas in China.

Keywords: p16 expression; Laryngeal squamous cell carcinoma; Biomarker; Prognostic value

\section{Introduction}

Head and neck squamous cell carcinoma (HNSCC) is a heterogeneous group of neoplasms. An estimated 551,000 new cases and over 306,000 deaths occurred secondary to HNSCC in 2008 worldwide [1]. Laryngeal squamous cell carcinoma (LSCC) is one of the most common type of the head and neck cancer. Although the principal risk factors for head and neck cancers remain tobacco smoking and alcohol abuse, human papilloma virus (HPV) infection has recently been found to be etiologically associated with $15-35 \%$ of cases of HNSCCs [2].

HPV is a double-stranded DNA, epitheliotropic virus belonging to the Papova viridae family. HPV infection is the most common sexually transmitted disease worldwide, with a prevalence rate ranging from 10 to $50 \%$ in sexually active women [3]. More than 200 different HPV genotypes have been described. In 1995, on the basis of mounting epidemiologic and molecular evidence, the International Agency for Research on Cancer recognized that HPV types 16 and 18 were carcinogenic in humans [4]. Its causative role in invasive cervical carcinomas has been well established [5]. HPV 16 is the predominant (90\% to $95 \%$ ) genotype detected in head and neck tumors, with different prevalence between anatomic sites [6].

Oncogenic activity of HPV is mediated by viral oncoproteins E6 and E7 that can lead to DNA instability. The E6 protein of high-risk HPV binds and induces the degradation of the p53 tumor suppressor protein via an ubiquitin mediated process. The E7 protein binds to $\mathrm{pRb}$, which dissociates $\mathrm{pRb} / \mathrm{E} 2 \mathrm{~F}$ complexes and thereby facilitates the expression of DNA 
replication proteins. In addition, the E6 oncoprotein interferes with DNA repair enzymes, and the E7 oncoprotein can induce structural and numerical chromosome abnormalities by the disruption of centrosome synthesis. This genetic instability can cause the emergence of tumorigenic cells [7].

The p16INK4a protein ( $p 16)$, a product of CDKN2A gene localized on chromosome 9p21, was identified as an inhibitor of cyclin-dependent kinase 4, the activity of which is critical in the regulation of the normal cell cycle [8]. In normal tissue cells, p16 is expressed at a very low level, which is under the detection limit of immunohistochemistry. Interestingly, its expression is found to be increased in response to inactivation of the p53 and pRb, caused by deregulated expression of E6 and E7 HPV oncoproteins in infected cells. Thus tests detecting p16 are used as a surrogate marker of HPV-induced oncogenesis [8].

Reports suggest an increase in the prevalence of HPVassociated oropharyngeal squamous cell carcinomas (OPSCC) and that these cancers are distinct from other head and neck cancers [9]. HPV-positive OPSCC tend to be poorly differentiated with basaloid morphology, presenting with a lower $\mathrm{T}$ stage and higher nodal status [2], but paradoxically better prognosis $[10,11,12]$. A recent study shows that $p 16$ is the single most important prognostic variable in OPSCC, surpassing traditional prognostic factors. It also highlights the need for routine p16 assessment in OPSCC [13].

It has been demonstrated that viral infection is a plausible cause for laryngeal carcinoma. The prevalence of HPV in LSCC has been reported in various studies from $7.4 \%$ to $58.8 \%$ [14]. However, the causal link between HPV and laryngeal carcinoma remains controversial and is not as well studied as in oropharyngeal carcinoma. Of all the studies that have been done most are focused on the European and American populations. The prevalence of HPV and prognostic value of p16 expression specifically in reference to Chinese population is unknown. The link between HPV infection and development of laryngeal carcinoma is influenced by geographical factors as it was confirmed in two large case-control studies [15]. Thus this retrospective study was performed to investigate p16 expression and its prognostic value in LSCC.

\section{Materials and Methods}

\section{Cases}

An electronic data search was conducted to identify all cases of LSCC diagnosed at Cancer Center of SunYat-sen University, Guangzhou, People's Republic of China, from the year 2000 to 2005. A total of 236 cases were retrieved, of these 151 were laryngectomies and 85 were biopsies.

\section{Immunohistochemical analysis}

The Hematoxylin and Eosin stained slides from all the 236 cases were reviewed and the diagnosis of squamous cell carcinoma was confirmed. One representative block from each case was examined by immunohistochemistry for p16 expression. Immunohistochemical studies were performed on $5 \mu \mathrm{m}$ sections of formalin-fixed, paraffin-embedded tissue from laryngeal biopsy and laryngectomy specimens. Slides were first de-paraffinized, and rehydrated. Antigen retrieval was carried out with $0.01 \mathrm{~mol} / \mathrm{L}$ citrate buffer at $\mathrm{pH}$ 6.0. The slides were then heated in an 800-W microwave oven for 15 minutes, cooled to room temperature, and rinsed in distilled water before staining. The slides were stained on the DAKO Autostainer (DAKO Corporation, Carpinteria, CA) using the EnVision (DAKO) staining reagents. The sections were first blocked for endogenous protein binding and peroxidase activity with an application of Dual Endogenous Block (DAKO) for 10 minutes, followed by a buffer wash. The sections were then incubated with a mouse monoclonal antibody specific for p16 (DAKO) at a $2.0 \mu \mathrm{g} / \mathrm{ml}$ concentration for 30 minutes. Sections were then incubated with the EnVision+ Dual Link reagent (a polymer conjugated with goat-anti-mouse-lg, and horseradish peroxidase) for 30 minutes, and treated with diaminobenzidine (DAB) and hydrogen peroxide, to produce the visible brown pigment. The sections were counterstained with hematoxylin, dehydrated, and coverslipped with permanent media. Sections of cervical dysplasia with known positivity of p16 were used as positive controls for p16 staining. Negative controls were performed by replacing the primary antibody with an isotype specific IgG control.

\section{Morphological evaluation}

Positive staining of p16 was defined as a dark brown staining of the nuclei and/or cytoplasmic staining, in the tumor cells. The immunostaining evaluation was done at low-power magnification $(<40 X)$ and was scored according to the following criteria: negative or 0 ( $0 \%$ cells staining), 1+ (<25\%cells staining), $2+(25-50 \%$ cells staining), and $3+(>50 \%$ cells staining). For statistical purposes tumors with any p16 expression were consider to be positive irrespective of intensity of staining.

\section{Statistical analysis}

Age, sex, tumor stage and grade, vital status and p16 status were collected as baseline variables. The distribution of each baseline variable was compared for p16 -positive and p16negative subgroups with the Wilcoxon rank sum test for continuous variables and the Fisher's exact test for categorical variables. A P value of less than 0.05 was considered to be statistically significant in all statistical analyses. Overall survival was measured from the date of laryngectomy or biopsy to the date of death, and was censored from the date of last followup. Median follow-up period was 5 years and 3 months (63 months, range 7-123 months). The overall survival was analyzed using Kaplan-Meier estimate and evaluated using the log-rank test for univariate analysis. 


\section{Results}

\section{Patients}

Table 1 showed that in 236 patients there were 228 men and 8 women, with a mean age of $58.5+/-10.06$ years. 72 patients (30.5\%) presented with Stage I disease, 69 (29.3\%) with Stage II disease, 64 (27.1\%) with Stage III disease and 31 (13.1\%) patients had Stage IV disease. Among the 236 LSCC cases 11 (4.6\%) were in situ, 87 (36.9\%) were well differentiated, 100 (42.4\%) were moderately differentiated and $38(16.1 \%)$ were poorly differentiated squamous cell carcinomas.

Table 1 Clinicopathological characteristics of patients with laryngeal carcinoma.

\begin{tabular}{|c|c|c|c|}
\hline & p16-Negative & p16-Postitive & P Value \\
\hline & $n=193$ & $n=43$ & \\
\hline \multicolumn{4}{|l|}{ Sex } \\
\hline Female & $4(50 \%)$ & $4(50 \%)$ & 0.04 \\
\hline Male & $189(83 \%)$ & $39(17 \%)$ & \\
\hline \multicolumn{4}{|l|}{ Age } \\
\hline Mean (SD) & $58(9.9)$ & $59(10.8)$ & 0.57 \\
\hline \multicolumn{4}{|l|}{ Stage } \\
\hline I & $58(79 \%)$ & $14(21 \%)$ & 0.77 \\
\hline II & $59(86 \%)$ & $10(14 \%)$ & \\
\hline III & $52(83 \%)$ & $12(17 \%)$ & \\
\hline IV & $24(81 \%)$ & $7(19 \%)$ & \\
\hline \multicolumn{4}{|l|}{ Grade } \\
\hline In situ & $10(92 \%)$ & $1(8 \%)$ & 0.39 \\
\hline w & $75(86 \%)$ & $12(14 \%)$ & \\
\hline $\mathbf{M}$ & $79(84 \%)$ & $21(16 \%)$ & \\
\hline $\mathbf{P}$ & $29(76 \%)$ & $9(24 \%)$ & \\
\hline \multicolumn{4}{|l|}{$\begin{array}{l}\text { Vital } \\
\text { Status }\end{array}$} \\
\hline Alive & $129(82 \%)$ & $30(18 \%)$ & 0.71 \\
\hline Dead & $64(83 \%)$ & $13(17 \%)$ & \\
\hline
\end{tabular}

\section{p16}

Fourty three of 236 (18\%) LSCC showed immunoreactivity for p16; with $21(48.8 \%)$ cases showing $3+$ staining, $5(11.6 \%)$ cases showing $2+$ staining and $17(39.6 \%)$ cases showing $1+$ staining. Though for analysis, cases were divided into positive (any p16 positivity, score $1+$ to $3+$ ) and negative groups (Figure 1). The clinicopathological features of the patients with laryngeal squamous cell carcinoma and p16 expression are summarized in Table 1. Age, tumor stage and grade, and vital status (alive or dead) were not associated with p16 expression.

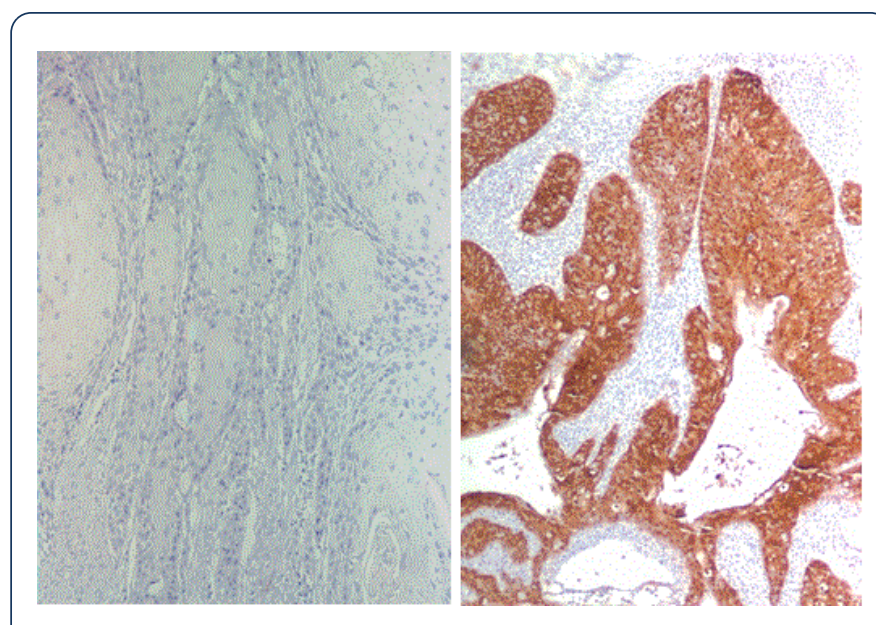

Figure 1 Immunohistochemical stains for p16 showing that laryngeal squamous cell carcinoma was negative for $\mathrm{p} 16$ (left) and was positive for p16 (right).

\section{Overall survival}

Overall survival was measured from the date of laryngectomy or biopsy to the date of death, and was censored from the date of last follow-up. Median follow-up period was 5 years and 3 months (63 months, range 7-123 months). KaplanMeier analysis showed that the 10 -year rate of overall survival was similar in patients with p16 positive tumors and p16 negative tumors ( $31 \%$ vs. $34 \% ; \mathrm{P}=0.28 ; 95 \%$ confidence interval [Cl], 0.34 to 1.37 ) (Figure 2).

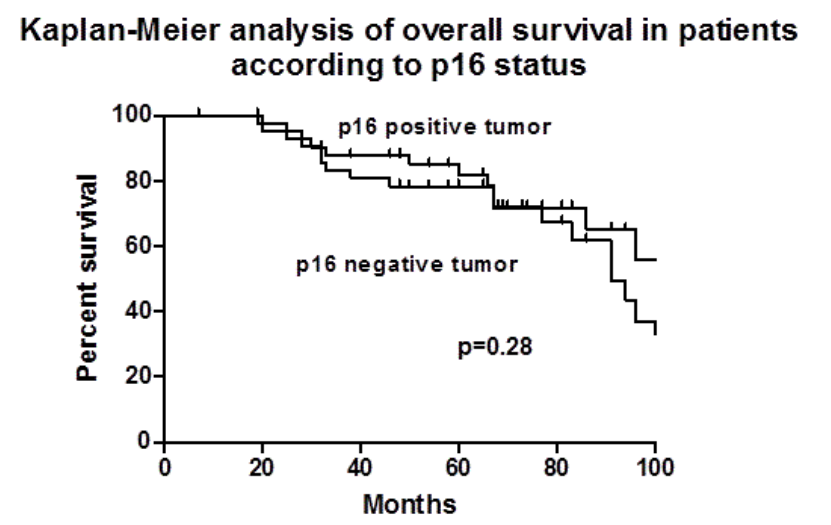

Figure 2 Kaplan-Meier analysis of overall survivals according to $\mathrm{p} 16$ status (positive verses negative) assessed by immunehistochemical analysis in total 236 Chinese patients with laryngeal squamous cell carcinomas. $P$ values were calculated by using the log-rank test.

\section{Discussion}

Carcinoma of the larynx accounts for $1.9 \%$ of all cancers in men and $0.3 \%$ in women. There were an estimated 156,877 new cases of LSCC around the world in 2012, with 83,376 deaths secondary to it [16]. Two major risk factors for the 
development of LSCC are tobacco smoking and alcohol abuse [17]. However, in approximately $5 \%$ of cases both of these risk factors are absent suggesting involvement of other etiological factors in tumorgenesis [18]. HPV has been linked with laryngeal carcinomas for the last 20 years [19] but its causal association has been controversial and inadequately evaluated.

P16 inactivation is a well-known mechanism involved in neoplastic transformation and progression of HNSCC. p16INK4a is inactivated in LSCC by mutation or homozygous deletion in $22 \%$ of cases each, and by hypermethylation in an additional $7 \%$. Nadal et al. showed that a number of mutated cases (with concomitant loss of heterozygosity, therefore fully inactivated p16INK4a) had normal or higher-than normal expression levels [20].

Numerous studies measured p16 expression by immunohistochemistry. The study done by Laco et al included 24 laryngeal carcinomas, and p16 was detected in 58\% [21]. Similarly, Tamas et al. [22], Fu et al. [23] and Mendelsohn et al. [24] reported p16 positivity in 39.5\% (15/38), 40\% (16/40), and $5.6 \%(1 / 18)$ glottic LSCC, respectively. A recent study in 2014 by Kalfert et al. [25] showed p16 expression in glottis LSCC of 15 out of 58 patients $(25.9 \%)$. We currently observed in Chinese population that 43 of $236(18 \%)$ LSCC cases showed immunoreacticity for $\mathrm{p} 16$. Our data showed that the p16 positive rate in LSCC of Chinese patients was lower than the p16 positive rate in previous studies that were predominantly focused on Caucasian population (Laco et al. and Kalfert et al., Tamas et al. and Mendelsohn et al. reported on cases from Czech Republic, Hungary and United States of America, respectively).

P16 expression has been well known as the single most important prognostic variable in OPSCC, with p16 positive OPSCC patients having better survival outcomes [13]. P16 overexpression was also proven to be associated with better prognosis of LSCC, while p16 negativity determined tumor progression and poor outcome in previous studies [26,27]. Nevertheless, the other studies on the prognostic role of $\mathrm{p} 16$ in laryngeal cancer present contradictory results. Duray et al. [28] despite of reporting the lowest rate of local recurrence of LSCC with p16 overexpression (20\% recurrence 5 years after diagnosis) did not find any statistically significant differences in p16 expression between the recurrent and disease-free survival cases in their study. Kalfert et al. [25] showed that the recurrence was revealed in $8(13.8 \%)$ patients with LSCC approximately 3 years after diagnosis and all cases were p16negative, however no statistically significant correlation was found ( $p=0.097)$ between $p 16$ expression of LSCC and cancer recurrence.

Our study is the first to describe p16 expression in a large cohort of Chinese patients with LSCC. The study demonstrated p16 expression with no prognostic value for Chinese patients with LSCC. Thus, p16 immunostaining cannot be used as a prognostic biomarker for Chinese patients with LSCC. The low expression rate of p16 in Chinese patients with LSCC and lack of prognostic value of p16 expression suggest that other pathogeneses rather than HPV infection may be more important for Chinese patients with LSCC.

\section{References}

1. Ferlay J, Shin HR, Bray F, Forman D, Mathers C, et al. (2010) Estimates of worldwide burden of cancer in 2008: GLOBOCAN. Int J Cancer 127: 2893-2917.

2. Gillison ML, Koch WM, Capone RB, Spafford M, Westra WH, et al. (2009) Evidence for a Causal Association Between Human Papillomavirus and a Subset of Head and Neck Cancers. J Natl Cancer Inst 92: 709-720.

3. Micheal EH (2000) Infection with human papillomavirus: update on epidemiology, diagnosis, and treatment. Curr Infect Dis Rep 2: 18-24.

4. IARC Working Group on the Evaluation of Carcinogenic Risks to Humans. Human papillomaviruses. IARC Monogr Eval Carcinog Risks Hum 64: 1-378.

5. Walboomers JM, Jacobs MV, Manos MM, Bosch FX, Kummer JA, et al. (1999) Human papillomavirus is a necessary cause of invasive cervical cancer worldwide. J Pathol 189: 12-19.

6. Kreimer AR, Clifford GM, Boyle P, Franceschi S (2005) Human papillomavirus types in head and neck squamous cell carcinomas worldwide: a systematic review. Cancer Epidemiol Biomarkers Prev 14: 467-475.

7. Duensing S, Münger K (2004) Mechanisms of genomic instability in human cancer: insights from studies with human papillomavirus oncoproteins. Int J Cancer 109: 157-162.

8. Serrano M, Hannon GJ, Beach D (1993) A new regulatory motif in cell-cycle control causing specific inhibition of cyclin D/CDK4. Nature 366: 704-707.

9. Gillison ML, D'Souza G, Westra W, Sugar E, Xiao W, et al. (2008) Distinct Risk Factor Profiles for Human Papillomavirus Type 16Positive and Human Papillomavirus Type 16-Negative Head and Neck Cancers. J Natl Cancer Inst 100: 407-420.

10. Weinberger PM, Yu Z, Haffty BG, Kowalski D, Harigopal M, et al. (2004) Prognostic Significance of p16 Protein Levels in Oropharyngeal Squamous Cell Cancer. Cli Cancer Res 10: 5684-5691.

11. Ragin CC, Taioli E (2007) Survival of squamous cell carcinoma of the head and neck in relation to human papillomavirus infection: Review and meta-analysis. Int J Cancer 121: 1813-1820.

12. Pai SI, Westra WH (2009) Molecular Pathology of Head and Neck Cancer: Implications for Diagnosis, Prognosis, and Treatment. Annu Rev Pathol 4: 49-70.

13. Oguejiofor KK, Hall JS, Mani N, Douglas C, Slevin NJ, et al. (2013) The prognostic significance of the biomarker p16 in oropharyngeal squamous cell carcinoma. Clinical Oncology 25: 630-638.

14. Torrente MC, Rodrigo JP, Haigentz M Jr, Dikkers FG, Rinaldo A, et al. (2011) Human papillomavirus infections in laryngeal cancer. Head and neck 33: 581-586.

15. Ribeiro KB, Levi JE, Pawlita M, Koifman S, Matos E, et al. (2011) Low human papillomavirus prevalence in head and neck cancer: results from two large case-control studies in high-incidence regions. Int J Epidemiol 40: 489-502. 
16. Ferlay J, Soerjomataram I, Dikshit R, Eser S, Mathers C, et al. (2015) Cancer incidence and mortality worldwide: Sources, methods and major patterns in GLOBOCAN 2012. Int J Cancer 136: 359-386.

17. Marshall JR, Graham S, Haughey BP, Shedd D, O'Shea R, et al. (1992) Smoking, alcohol, dentition and diet in the epidemiology of oral cancer. Eur J Cancer B Oral Oncol 28: 9-15.

18. Baumann JL, Cohen S, Evjen AN, Law JH, Vadivelu S, et al. (2009) Human papillomavirus in early laryngeal carcinoma. The Laryngoscope 119: 1531-1537.

19. Syrjänen KJ, Surjänen SM (1981) Histological evidence for the presence of condylomatous epithelial lesions in association with laryngeal squamous cell carcinoma. ORL J Otorhinolaryngol Relat Spec 43: 181-194.

20. Nadal A, Cardesa A (2003) Molecular biology of laryngeal squamous cell carcinoma. Virchows Archiv 442: 1-7.

21. Laco J, Slaninka I, Jirasek M, Celakovsky $P$, Vosmikova $H$, et al. (2008) A High-risk human papillomavirus infection and p16INK4a protein expression in laryngeal lesions. Pathol Res Pract 204: 545-552.

22. Tamás L, Szentkúti G, Eros $M$, Dános $K$, Brauswetter D, et al. (2011) Differential biomarker expression in head and neck cancer correlates with anatomical localization. Pathol Oncol Res 17: 721-727.
23. Fu ZJ, Ma ZY, Wang QR, Lei DP, Wang R, et al. (2008) Overexpression of CyclinD1 and underexpression of p16 correlate with lymph node metastases in laryngeal squamous cell carcinoma in Chinese patients. Clin Exp Metastasis 25: 887-892.

24. Mendelsohn AH, Lai CK, Shintaku IP, Elashoff DA, Dubinett SM, et al. (2010) Histopathologic findings of HPV and p16 positive HNSCC. The Laryngoscope 120: 1788-1794.

25. Kalfert D, Celakovsky P, Laco J, Ludvikova M (2014) The role of protein p16(INK4a) in glottic laryngeal squamous cell carcinoma. Pathol Oncol Res 20: 909-915.

26. Silva SD, Nonogaki S, Soares FA, Kowalski LP (2012) p16 (INK4a) has clinicopathological and prognostic impact on oropharynx and larynx squamous cell carcinoma. Braz J Med Biol Res 45: 1327-1333.

27. Swellam M, El-Arab LR, Adly A (2008) Prognostic value of cellcycle regulators and cellular biomarkers in laryngeal squamous cell carcinoma. Clin Biochem 41: 1059-1066.

28. Duray A, Descamps G, Arafa M, Decaestecker C, Remmelink M, et al. (2011) High incidence of high-risk HPV in benign and malignant lesions of the larynx. Int J Oncol 39: 51-59. 